\title{
Audit Tata Kelola Teknologi Informasi Menggunakan Framework COBIT 5 Pada PT. Bisma Tunas Jaya Sentral
}

\author{
Khairunnisa Devanti ${ }^{1}$, Wayan Gede Suka Parwita ${ }^{2}$, I Kadek Budi Sandika*3 \\ ${ }^{1,2,3}$ Program Studi Teknik Informatika, STMIK STIKOM Indonesia, Bali, Indonesia \\ e-mail: *1k khairunnisa.devanti@gmail.com, ${ }^{2}$ gede.suka@ gmail.com, \\ budi.santika@gmail.com
}

\begin{abstract}
Abstrak
Abstrak PT. Bisma Tunas Jaya Sentral adalah perusahaan yang bergerak di bidang penjualan barang jadi (khususnya sepeda motor), suku cadang (sparepart), dan servis sepeda motor khusus brand Yamaha. Untuk menunjang pelayanan bisnisnya, digunakan layanan TI berupa perangkat lunak dan perangkat keras yang digunakan dalam proses bisnis. Untuk memastikan terdapat pengelolaan TI yang optimal, dilakukan pengukuran level tata kelola TI yang telah berjalan dan membandingkannya dengan level yang diharapkan manajemen. Pengukuran ini mengacu pada domain COBIT 5. Langkah - langkah penelitian ini dimulai dari perencanaan penelitian, perancangan instrumen pengumpulan data, pengumpulan data dan melakukan pengolahan data hingga melakukan evaluasi akhir yang menghasilkan saran rekomendasi perbaikan pengelolaan sesuai dengan maturity model COBIT. Hasil dari pengolahan data yang sudah dilakukan menunjukkan bahwa metode tata kelola infrastruktur TI yang sudah berjalan di PT Bisma Tunas Jaya belum cukup baik. Dibuktikan dengan nilai gap yang cukup tinggi antara level pengelolaan saat ini dengan level yang diinginkan manajemen.
\end{abstract}

Kata kunci-Audit, Tata Kelola Teknologi Informasi, Perangkat Keras, Perangkat Lunak, , Maturity Model, COBIT 5

\begin{abstract}
Abstract PT. Bisma Tunas Jaya Sentral is a company engaged in the sale of finished goods (especially motorcycles), spare parts, and motorcycle service specifically for the Yamaha brand. To support business services, IT services in the form of software and hardware are used in business processes.To ensure optimal IT management, measurements of the level of IT governance that have been carried out and compare it with the level expected by management. This measurement refers to the COBIT domain 5. The steps of this study start from research planning, design of data collection instruments, data collection and data processing to conduct a final evaluation that results in recommendations for improved management in accordance with the maturity of the COBIT model.The results of data processing that have been carried out indicate that the IT infrastructure management method that is already running at PT Bisma Tunas Jaya is not good enough. It is proven by the high gap between the current management level and the level desired by management
\end{abstract}

Keywords - Audit, Information Technology Governance, Hardware, Software,, Maturity Model, COBIT 5 


\section{PENDAHULUAN}

Seiring dengan perkembangan teknologi, teknologi informasi (TI) telah menjadi kebutuhan untuk memenuhi visi dan misi suatu perusahaan. Dalam lingkungan bisnis yang kompetitif, perusahaan menyadari manfaat potensial yang dapat dihasilkan oleh TI. Hal ini mendorong ekspektasi yang tinggi terhadap outcome dan manfaat TI, berupa keefektifan dalam pelayanan, kemudahan penggunaan dan perbaikan secara terus menerus.

PT. Bisma Tunas Jaya Sentral adalah perusahaan yang bergerak di bidang penjualan barang jadi (khususnya sepeda motor), suku cadang (sparepart), dan servis sepeda motor khusus brand Yamaha. Proses bisnis yang meliputi penerimaan servis, transaksi jual beli unit sepeda motor dan sparepart, hampir seluruhnya membutuhkan TI. Namun, perkembangan TI di perusahaan ini belum optimal. Saat konsumen mendaftar servis, terdapat antrian yang cukup panjang dikarenakan proses daftar servis tiap konsumen yang relatif lama. Demikian halnya saat pembelian sparepart, perangkat hardware yang ada tidak sebanding dengan jumlah pegawai sehingga pegawai terpaksa harus mengantri saat mencetak nota penjualan. Kemudian, terdapat proses - proses lain yang pencatatannya masih dilakukan secara manual, sehingga waktu pelayanan relatif lama, rawan terjadi kesalahan, dan kehilangan data karena sistem penyimpanan dan pengolahan data belum terkomputerisasi.

Akan tetapi, investasi TI di perusahaan relatif besar, terlebih pada perusahaan dengan intensitas pengendalian teknologi informasi tinggi. Maka dengan pengadaan yang cukup besar, diharapkan investasi TI ini berhasil. Agar berhasil dengan baik, TI dalam perusahaan tidak cukup hanya diatur oleh bagian TI saja, tetapi harus dikelola secara profesional, yakni memerlukan keterlibatan eksekutif agar selaras dengan visi \& misi perusahaan dan mendukung pencapaian tujuan perusahaan. Pada PT. Bisma Tunas Jaya Sentral, TI disediakan oleh Yamaha Pusat, dan dikelola oleh Tim Pemeliharaan Sistem (IT Team) atas komando dari Pemilik (Owner).

Sistem yang digunakan di PT. Bisma Tunas Jaya Sentral sebelumnya merupakan sistem berbasis desktop yang telah digunakan sejak tahun 2014 hingga pertengahan tahun 2018. Ditemukan kelemahan berupa sulitnya pengawasan data dari Yamaha Pusat (Jakarta) dikarenakan sistem bersifat offline, selain itu ketika terdapat pembaruan sistem diinformasikan via e-mail kepada seluruh Kepala Tim daerah yang kemudian diteruskan ke tiap dealer. Pemberitahuan melalui e-mail dirasakan sangat lambat, karena tidak semua dealer intens menggunakan e-mail, dan terdapat tahap export tools yang belum tentu dipahami oleh seluruh karyawan, sehingga banyak dealer yang mengalami ketertinggalan informasi dan update sistem. Juga terdapat permasalahan berupa proses pemesanan sparepart belum tersedia dalam sistem sehingga masih dilakukan pencatatan secara manual.

Semenjak pertengahan tahun 2018, perusahaan mengikuti anjuran Yamaha Pusat untuk upgrade sistem D-PACK berbasis web. Permasalahan berupa pembaruan sistem terselesaikan. Pembaruan terjadwal oleh Yamaha Pusat dan diperbarui otomatis karena sistem berbasis web juga pengawasan data dapat dilakukan secara online. Namun masalah berupa pemesanan sparepart masih belum terselesaikan, pesanan sparepart masih dicatat secara manual sehingga pelayanan sparepart tidak efektif.

Maka diperlukan sebuah mekanisme kontrol atau audit teknologi informasi,untuk mengukur tingkat kematangan penerapan TI di PT. Bisma Tunas Jaya Sentral. Audit ini pertama kali dilakukan, mengingat permasalahan berupa pelayanan yang lambat masih tetap terjadi meskipun telah terdapat pembaruan sistem. Salah satu standar penting dan efektif untuk diterapkan dalam audit adalah COBIT. Penggunaan bantuan dan metode COBIT memberi manfaat untuk perusahaan agar dapat menangani permasalahan teknis melalui pengendalian terhadap masing-masing proses TI. Sehingga, berdasarkan masalah yang ada, dibutuhkan suatu audit tata kelola teknologi informasi PT. Bisma Tunas Jaya Sentral dengan standar COBIT 5.

JSIKTI Vol. 2, No. 2, Desember 2019: $65-76$ 


\section{METODE PENELITIAN}

\subsection{Penelitian Terdahulu}

Penelitian dengan topik audit teknologi informasi sudah pernah dilakukan sebelumnya, salah satunya oleh [1] Penelitian berjudul Tata Kelola Teknologi Informasi Menggunakan Framework COBIT 5 pada PT Santani Agro Persada. Audit belum pernah dilakukan sebelumnya, namun mengingat TI merupakan aset penting bagi perusahaan, maka evaluasi terhadap tata kelola teknologi informasi dianggap perlu untuk dilakukan, untuk mengukur tingkat kematangan TI dan mencari permasalahan yang terjadi pada proses bisnis untuk menaikkan tingkat kematangan sistem yang ada sehingga sesuai dengan harapan manajemen perusahaan dan dapat mempertemukan kebutuhan stakeholder serta menjaga integritas datanya. Audit dilakukan untuk mengukur tingkat kematangan aplikasi A Ueromoney Institutional Investor Company (EMIS) dan menemukan kesenjangan (gap) yang terjadi dengan membandingkan tingkat kematangan saat ini dengan tingkat kematangan yang diharapkan perusahaan, yang akan menjadi landasan dalam pemberian rekomendasi perbaikan sistem agar aplikasi EMIS dapat ditingkatkan lagi keakuratannya dan menjaga integritas data claim penjualan. Didapatkan hasil bahwa maturity level sistem informasi claim penjualan pada aplikasi EMIS saat ini berada pada level 4 (manage and measurable) yang berarti aplikasi EMIS sudah dimonitor dan diukur dengan baik

Penelitian lainnya dilakukan oleh [2], yang berjudul Audit Tata Kelola Teknologi Informasi Menggunakan Framework COBIT 5 (Studi Kasus: PT.Indocom Tambak Udang Lampung) Penelitian ini dilakukan di PT.Indocom Tambak Udang Lampung, yang merupakan Unit Pelaksana Teknis (UPT) di bidang pengembangan budidaya udang yang berada di bawah dan bertanggungjawab kepada Direktorat Jendral Perikanan Budidaya. Audit dilakukan karena kegiatan tata kelola keamanan informasi belum dilakukan secara maksimal. Untuk mengantisipasi terjadinya kendala seperti sumber daya manusia yang kurang memahami aplikasi e-SKP (elektronik Sasaran Kinerja Pegawai) sehingga berpotensi terjadinya error pada aplikasi, maka dilakukan metode pengelolaan teknologi informasi menggunakan kerangka kerja COBIT 5. Didapatkan hasil audit tata kelola teknologi informasi bahwa maturity level e-SKP saat ini berada pada level 2 (repeatable) yang berarti dalam penggunaan e-SKP, tidak terdapat pelatihan formal atau pengomunikasian prosedur standar tanggung jawab diserahkan kepada individu masing-masing, sehingga sangat mungkin terjadi error.

Penelitian yang penulis lakukan berfokus pada software dan hardware yang digunakan dalam operasional bisnis PT. Bisma Tunas Jaya Sentral, berupa sistem D-PACK WEB, Fingerprint Absensi Karyawan, penyediaan komputer bagi tiap divisi, dan pengelolaan jaringan kumputer. Penulis menggunakan Framework COBIT 5. Audit dilakukan setelah ditemukan permasalahan berupa pelayanan yang lambat masih tetap terjadi meskipun telah dilakukan pembaruan terhadap sistem yang ada, yakni perubahan dari berbasis desktop ke berbasis website

\subsection{Definisi Tata Kelola Teknologi Informasi}

Tata kelola TI memiliki definisi inklusif yang mencakup Sistem Informasi (SI), teknologi dan komunikasi, bisnis dan hukum serta isu-isu lain yang melibatkan hamper seluruh pemangku kepentingan (stakeholder), baik direktur, manajemen eksekutif, pemilik proses, supplier, pengguna TI bahkan pengaudit SI/TI. Pembentukan da penyusunan tata kelola tersebut merupakan tanggung jawab dari jajaran direksi dan manajemen eksekutif [3].

Definisi tata kelola TI adalah sebagai penspesifikasian hak keputusan dan rerangka akuntabilitas untuk mengarahkan perilaku yang diinginkan dalam penggunaan TI [4]. Mereka juga menegaskan bahwa tata kelola TI tidak sekedar tentang pembuatan keputusan spesifik 
tetapi lebih pada penentuan siapa yang secara sistematis membuat dan berkontribusi pada keputusan tersebut.

IT Governance atau tata kelola teknologi informasi merupakan tanggung jawab eksekutif dari sebuah dewan direksi dan manajemen tingkat atas [5], begitu juga dengan sistem e-government pada pemerintahan [6]. Tata kelola terdiri dari kepemimpinan, struktur organisasi dan proses yang memastikan bahwa strategi dan tujuan organisasi perusahaan dan TI tetap terjaga dan berkelanjutan.

ITGI (2003) menyebutkan "Fundamentally, IT Governance is concerned about two things: IT's delivery of value to the business and mitigation of IT risks. The first is driven by strategic alignment of IT with the business. The second is driven by embedding accountability into the enterprise. Both need to be measured adequately" [5]. Pernyataan ini menandakan bahwa terdapat 5 fokus area dalam tata kelola teknologi informasi, yaitu penyampaian nilai, penyelarasan strategis, manajemen sumber daya, manajemen risiko, dan manajemen kinerja. Penentuan manajemen juga dapat mempengaruhi kinerja karyawan, sehingga dibutuhkan sistem pendukung keputusan yang dapat menilai kinerja karyawan [7]

\section{2 Definisi Audit Tata Kelola Teknologi Informasi}

Menurut Fauzan dan Latifah (2015) audit adalah suatu proses yang sistematis untuk memperoleh dan menilai bukti-bukti secara objektif, yang berkaitan dengan tindakan-tindakan dan kejadian-kejadian ekonomi untuk menentukan tingkat kesesuaian dengan kriteria yang telah diterapkan dan mengkomunikasikan hasilnya kepada pihak-pihak yang berkepentingan.

Auditing menurut Alvin A. Arens,[8] adalah :"Auditing is the accumulation and evaluation of evidence about information, and established criteria. Auditing should be done by a competent, independent person", yang berarti audit adalah akumulasi dan evaluasi bukti tentang informasi, dan kriteria yang ditetapkan. Audit harus dilakukan oleh orang yang kompeten dan independen.

Dalam bidang TI, aktivitas audit dilakukan demi memberikan gambaran proses TI yang berlangsung di perusahaan masa kini kemudian mengamati, menganalisis dan menyesuaikan gambaran tersebut dengan ketetapan, standar, regulasi dan hukum yang berlaku [3]. Penyesuaian tersebut menghasilkan rekomendasi proses yang perlu mendapatkan perhatian pihak manajemen agar dapat diperbaiki dan disempurnakan sehingga TI dapat memberikan dukungan yang optimal terhadap bisnis.

TI diaplikasikan dalam perusahaan akan mempengaruhi seberapa jauh perusahaan telah mencapai visi, misi, ataupun tujuan strategisnya. Karena itulah, perusahaan perlu mengevaluasi pengelolaan TI tersebut yang menjadi kian penting sebaga bagian dari Tata Kelola Perusahaan secara keseluruhan [3].

Audit memerankan peranan penting dalam pengimplementasian Tata Kelola TI di perusahaan. Besarnya risiko yang mungkin muncul akibat penerapan TI di suatu perusahaan, membuat audit SI/TI semakin penting untuk dilakukan.

\section{3 COBIT}

"COBIT (Control Objectives for Information and Technology) merupakan model yang didesain untuk mengendalikan fungsi TI [9]. Model ini sebenarnya dikembangkan oleh Information System Audit and Control Foundation (ISACF), lembaga peneltian untuk Information Systems Audit and Control Assoction (ISACA). Tahun 1999 tugas ISACF untuk COBIT ditransfer ke IT Governance Institute (ITGI), yang merupakan badan idependen di dalam ISACA". "COBIT (Control Objectives for Information and Technology) adalah kerangka dari best practices manajemen TI yang membantu organisasi untuk memaksimalkan keuntungan bisnis dari organisasi TI mereka.”. COBIT adalah sekumpulan dokumentasi best practice untuk IT governance yang dapat membantu auditor, pengguna (user) dan manajemen,

JSIKTI Vol. 2, No. 2, Desember 2019: $65-76$ 
untuk menjebatani gap antara risiko bisnis, kebutuha control dan masalah-masalah teknis TI. COBIT dapat membantu auditor, manajemen dan pengguna akhir (end user) untuk menjembatani gap antara risiko bisnis, kebutuhan kontrol dan permasalahan- permasalahan teknis. Selain itu, COBIT juga memberikan panduan yang berorientasi pada bisnis, dan karena itu proses bisnis owner dan manajer, termasuk juga auditor dan user, diharapkan dapat memanfaatkan panduan ini dengan sebaik-baiknya.

COBIT adalah sekumpulan dokumentasi best practices untuk IT governance yang dapat membantu auditor, pengguna (user), dan manajemen, untuk menjembatani gap antara risiko bisnis, kebutuhan kontrol dan masalah-masalah teknis TI [8]. COBIT bermanfaat bagi auditor karena merupakan teknik yang dapat membantu dalam identifikasi IT controls issue. COBIT berguna bagi para IT users karena memperoleh keyakinan atas kehandalan sistem aplikasi yang dipergunakan. Sedangkan para manajer memperoleh manfaat dalam keputusan investasi di bidang IT serta infrastruktruknya, menyusun strategis IT Plan, menentukan information architecture, dan keputusan atas procurement (pengadaan/pembelian) mesin. Disamping itu, dengan keterandalan sistem informasi yang ada pada perusahaanya diharapkan berbagai keputusan bisnis dapat didasarkan atas informasi yang ada. COBIT mendukung manajemen dalam mengoptimumkan investasi TI-nya melalui pengukuran yang akan memberikan sinyal bahaya bila suatu kesalahan atau risiko akan atau sedang terjadi. Manajemen perusahaan harus memastikan bahwa sistem kendali internal perusahaan bekerja dengan baik, artinya dapat mendukung proses bisnis perusahaan yang secara jelas menggambarkan bagaimana setiap aktivitas kontrol individu memenuhi tuntunan dan kebutuhan informasi secara efeknya terhadap sumberdaya TI perusahaan. Sumberdaya TI merupakan suatu elemen yang sangat disoroti COBIT, termasuk pemenuhan kebutuhan bisnis terhadap: efektivitas, efisiensi, kerahasiaan, keterpaduan, ketersediaan, kepatuhan pada kebijakan/ aturan dan keandalan informasi (effectiveness, efficiency, confidentiality, integrity, availability, compliance, dan reliability).

\section{4 Analisis GAP}

Gap analisys merupakan salah satu alat yang dapat digunakan untuk mengevaluasi kinerja karyawan [10]. Gap analisys atau analis kesenjangan juga merupakan salah satu langkah yang sangat penting dalam tahapan perencanaan maupun tahap evaluasi kerja. Metode ini merupakan salah satu metode yang paling umum digunakan dalam pengelolaan manajemen internal suatu lembaga. Secara harfiah "gap" mengidentifikasikan adanya suatu perbedaan antara satu hal dengan hal lainnya. Analisis kesenjangan akan memicu organisasi atau perusahaan untuk merenung status dan kemampuan apa yang saat ini dimiliki oleh organisasi dan bertanya ingin berada dimana di masa depan. Jadi dengan lain kata analisa gap adalah studi yang dibuat untuk mengidentifikasi apakah sistem saat ini telah memenuhi kebutuhan. Dengan sendirinya alternatif-alternatif akan dikembangkan pada saat gap fungsi ditemukan. Gap diubah sesuai dengan proses bisnis, laporan yang diinginkan atau penyesuaian perangkat yang digunakan.

\subsection{Teknik Pengumpulan Data}

Pengumpulan data merupakan salah satu tahapan sangat penting dalam penelitian. Teknik pengumpulan data yang benar akan menghasilkan data yang memiliki kredibilitas tinggi, dan sebaliknya [11]. Oleh karena itu, tahap ini tidak boleh salah dan harus dilakukan dengan cermat sesuai prosedur. Sebab, kesalahan atau ketidaksempurnaan dalam metode pengumpulan data akan berakibat fatal, yakni berupa data yang tidak kredibel, sehingga hasil penelitiannya tidak bisa dipertanggungjawabkan. Hasil penelitian demikian sangat berbahaya, lebih-lebih jika dipakai sebagai dasar pertimbangan untuk mengambil kebijakan publik.
1. Wawancara
2. Observasi
3. Kuesioner
4. Dokumentasi, dan Tinjuan Pustaka 


\section{6 Tahapan Penelitian}

Tahapan dalam penelitian terbagi menjadi beberapa aktivitas antara lain, Tahap pertama dalam penelitian ini adalah melakukan studi visi dan misi perusahaan. Yang dilanjutkan dengan tahap kedua, yakni melakukan identifikasi masalah terhadap tata kelola TI yang berjalan di PT. Bisma Tunas Jaya Sentral. Proses analisis tata kelola di lakukan untuk mengidentifikasikan tujuan bisnis dan tujuan TI yang berjalan untuk dapat menentukan kondisi lapangan saat ini (sebelum penelitian).

Setelah kondisi saat ini telah ditetapkan maka dilakukan tahap ketiga, studi literatur berupa penelitian serupa. Ditemukan penelitian terdahulu dengan kerangka audit serupa, yakni COBIT 5. Didasarkan atas penelitian ini, penulis mengikuti alur dan mengidentifikasi domain. Selanjutnya, di tahap keempat penulis membuat perancangan tahapan audit yang akan dilakukan, lalu dilanjutkan dengan pemetaan tujuan bisnis dan tujuan TI PT. Bisma Tunas Jaya Sentral yang dilanjutkan dengan pemilihan domain sebagai tahap kelima. Pemetaan mengacu pada panduan pemetaan Enterprise Goals, IT-related Goals untuk menyeleraskan tujuan bisnis dan TI perusahaan berdasarkan standar COBIT 5. Dari pemetaan tersebut, didapatkan domaindomain yang dibutuhkan dalam proses audit. Lalu dilanjutkan dengan pengembangan instrumen pengumpulan data dari domain yang telah dipilih.

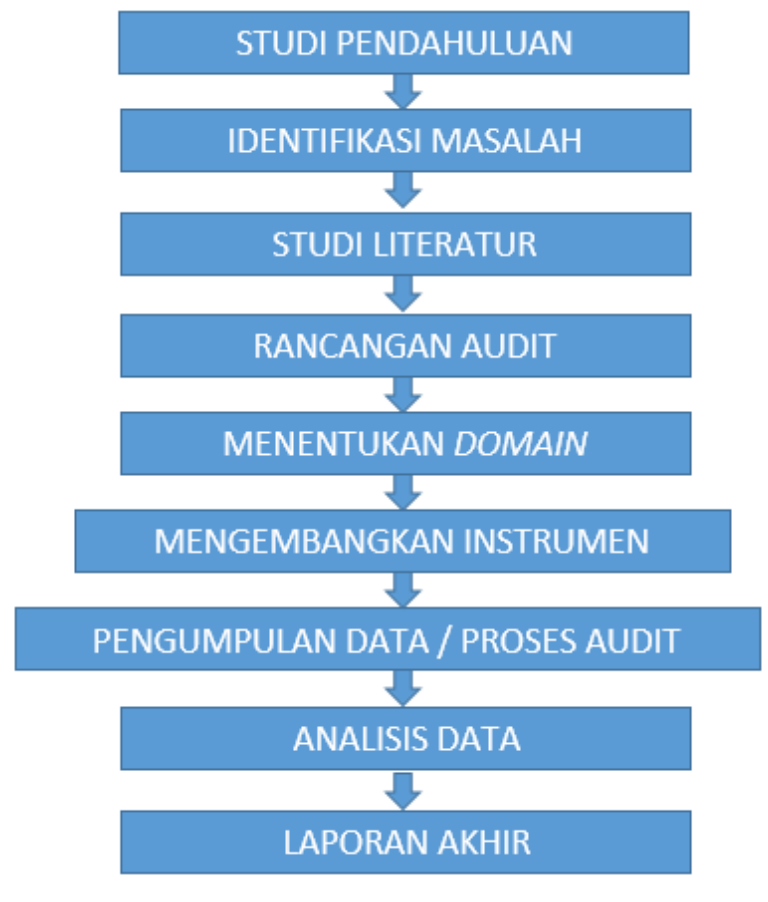

Gambar 1 Tahapan Penelitian COBIT 5

Tahap ketujuh adalah pengumpulan data dari pihak yang terlibat dengan proses bisnis. Data - data inilah yang selanjutnya akan dianalisis dengan maturity level. Dengan menganalisis hasil pengumpulan data didapatlah nilai-nilai yang sudah terpilih (hasil perhitungan) untuk tiap domain yang menunjukan suatu tingkat kematangan area domain tersebut. Pada tahap kedelapan, penelitian dilanjutkan dengan analisis gap dimana peneliti mendapatkan temuantemuan dari hasil penelitian, menganalisisnya dan memberikan skala perbandingan dari hasil maturity level saat ini dan target maturity level yang diharapkan oleh perusahaan.

Sehingga berdasarkan hasil analisis terhadap temuan-temuan yang ada dapat diberikan rekomendasi perbaikan untuk mencapai target yang diharapkan oleh PT. Bisma Tunas Jaya Sentral sebagai tahap terakhir dari penelitian. 


\section{HASIL DAN PEMBAHASAN}

\subsection{Domain EDM (Evaluate, Direct and Monitor)}

Dari sesi wawancara yang dilakukan untuk menilai Domain EDM, didapatkan rekap hasil wawancara pada Tabel 1

Tabel 1 Perhitungan Rata - Rata Domain EDM

\begin{tabular}{|c|c|c|c|c|c|}
\hline EDM & VINA & NERI & JON & DONALD & Rata-rata \\
\hline $\mathbf{1}$ & 5 & 5 & 3 & 5 & 4,50 \\
\hline $\mathbf{2}$ & 5 & 5 & 3 & 4 & 4,25 \\
\hline $\mathbf{3}$ & 3 & 3 & 3 & 3 & 3,00 \\
\hline $\mathbf{4}$ & 3 & 4 & 3 & 4 & 3,50 \\
\hline $\mathbf{5}$ & 5 & 5 & 5 & 5 & 5,00 \\
\hline
\end{tabular}

Berikut adalah analisa gap current maturity dan expected maturity domain EDM :

Tabel 2 Analisa Gap Domain EDM

\begin{tabular}{|c|c|c|c|c|}
\hline No & Pertanyaan & $\begin{array}{l}\text { Current } \\
\text { Maturity }\end{array}$ & $\begin{array}{l}\text { Expected } \\
\text { Maturity }\end{array}$ & $\begin{array}{c}\text { Analisa } \\
\text { Gap }\end{array}$ \\
\hline 1 & $\begin{array}{l}\text { Menurut anda, bagaimana tata kelola } \\
\text { teknologi informasi (TI) yang sedang berjalan } \\
\text { di perusahaan saat ini? }\end{array}$ & 4,50 & 5,00 & 0,50 \\
\hline 2 & $\begin{array}{l}\text { Menurut anda, bagaimana penyampaian } \\
\text { manfaat TI terhadap proses bisnis yang } \\
\text { berjalan? }\end{array}$ & 4,25 & 5,00 & 0,75 \\
\hline 3 & $\begin{array}{l}\text { Menurut anda, bagaimana optimalisasi } \\
\text { manajemen risiko terhadap TI yang } \\
\text { digunakan dalam proses bisnis di perusahaan } \\
\text { anda? }\end{array}$ & 3,00 & 5,00 & 2,00 \\
\hline 4 & $\begin{array}{l}\text { Menurut anda, bagaimana optimalisasi } \\
\text { sumber daya TI yang ada di perusahaan } \\
\text { anda? }\end{array}$ & 3,50 & 5,00 & 1,50 \\
\hline 5 & $\begin{array}{l}\text { Menurut anda, apakah penyampaian } \\
\text { informasi kepada pihak-pihak yang } \\
\text { berkepentingan cukup transparan? }\end{array}$ & 5,00 & 5,00 & 0 \\
\hline & Rata-rata & 4,05 & 5,00 & \\
\hline
\end{tabular}

Adapun analisis dari hasil wawancara secara umum dapat dilihat dalam tabel-tabel sebagai berikut :

Berdasarkan Tabel 1 sampai 3 di atas, dapat diketahui bahwa Expected Maturity yang ditetapkan oleh Manajemen untuk domain EDM adalah pada level 5,00 (Optimized) atas setiap subbabnya. Gap tertingggi adalah 2,00, di pertanyaan ketiga, merefleksikan EDM03, yakni memastikan optimalisasi manajemen risiko terhadap TI. Pada pertanyaan kelima, yang merefleksikan EDM05 yakni memastikan transparansi Informasi, tidak ada gap, yang membuktikan penyampaian informasi kepada pemangku kepentingan bersifat transparan dan sudah berjalan sesuai harapan manajemen.

Adapun rata - rata keseluruhan dari kelima pertanyaan yang menggambarkan Domain EDM adalah 4,05, yang berada pada level Managed, yang berarti manajemen telah mengawasi dan mengukur kepatuhan prosedur dan mengambil tindakan / solusi atas masalah yang muncul. TI yang ada sudah mampu menjadi penunjang utama pelayanan bisnis. 
Tabel 3 Deskripsi Domain EDM01

\begin{tabular}{|l|c|l|}
\hline Control Objective & $\begin{array}{l}\text { Rata- } \\
\text { Rata }\end{array}$ & Maturity Level \\
\hline $\begin{array}{l}\text { EDM01 - Memastikan } \\
\text { Pengaturan dan Tata Kelola TI }\end{array}$ & 4,50 & Managed \\
\hline
\end{tabular}

Deskripsi COBIT :

- Sudah terdapat pengelolaan TI yang baik, dengan adanya penanggung jawab TI yang mengidentifikasi kebutuhan TI dan membuat keputusan berdasarkan desain tata kelola saat ini dan di masa mendatang, sesuai dengan Rencana Strategis PT. Bisma Tunas Jaya Sentral

- Sudah adanya pengarahan dari penanggungjawab TI, sehingga Tata Kelola TI sesuai dengan kebutuhan bisnis, yang kemudian dilakukan pengarahan kepada pengguna untuk mengoptimalkan penggunaan TI

- Sudah dilakukan monitoring / pemantauan namun belum ada evaluasi terjadwal yang menilai apakah tata kelola yang berjalan sudah efektif dan efisien.

Analisa Gap antara Current Maturity dan Expected Maturity ditampilkan melalui grafik yang dapat dilihat pada gambar 4.1.

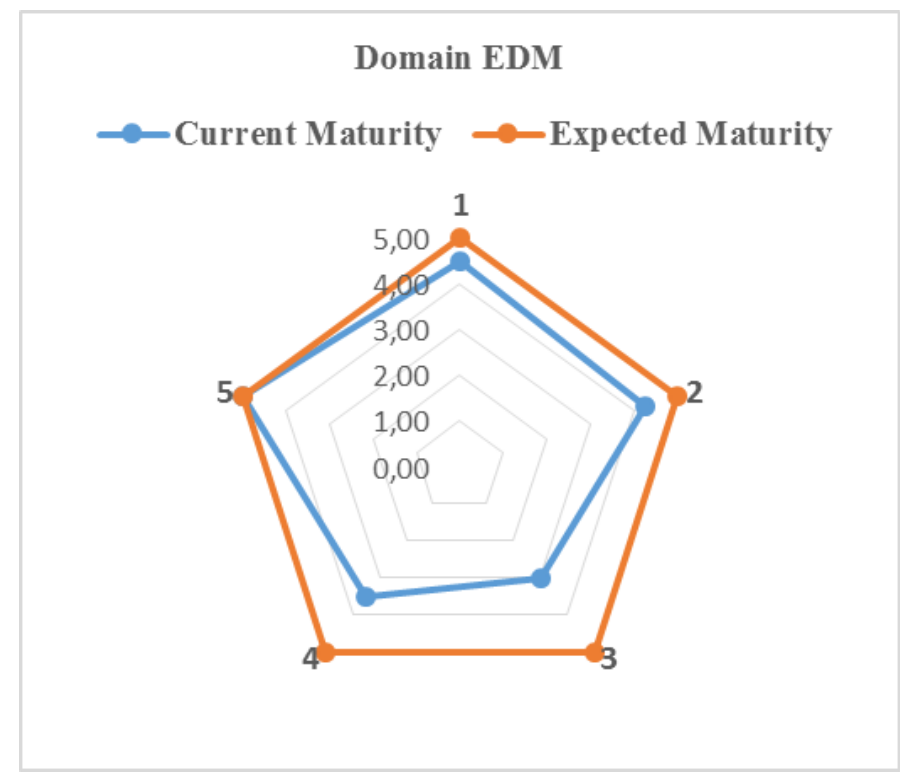

Gambar 2 Tampilan Grafik Current dan Target Maturity Level Domain EDM

\subsection{Domain APO (Align, Plan and Organize)}

Penilaian Maturity Level untuk domain APO tercantum dalam tabel 4.8 Analisa Gap Domain APO. 
Tabel 4 Analisa Gap Domain APO

\begin{tabular}{|c|l|c|c|c|}
\hline No & \multicolumn{1}{|c|}{ Pertanyaan } & $\begin{array}{c}\text { Current } \\
\text { Maturity }\end{array}$ & $\begin{array}{c}\text { Expect } \\
\text { Maturi } \\
\text { ty }\end{array}$ & $\begin{array}{c}\text { Analisa } \\
\text { Gap }\end{array}$ \\
\hline \hline 1 & $\begin{array}{l}\text { Menurut anda, bagaimana pengelolaan } \\
\text { kerangka tata kelola manajemen TI ? }\end{array}$ & 1,00 & 5,00 & 4,00 \\
\hline 2 & $\begin{array}{l}\text { Menurut anda, bagaimana pengelolaan strategi } \\
\text { TI yang dilakukan oleh perusahaan saat ini? }\end{array}$ & 5,00 & 5,00 & 0 \\
\hline 3 & $\begin{array}{l}\text { Menurut anda, bagaimanakah arsitektur } \\
\text { perusahaan saat ini? }\end{array}$ & 1,00 & 5,00 & 4,00 \\
\hline 4 & $\begin{array}{l}\text { Menurut anda, bagaimana inovasi TI yang } \\
\text { terjadi di perusahaan anda? }\end{array}$ & 5,00 & 5,00 & 0 \\
\hline 5 & $\begin{array}{l}\text { Menurut anda, bagaimana pengelolaan untuk } \\
\text { perkembangan pencapaian perusahaan anda? }\end{array}$ & 4,00 & 5,00 & 1,00 \\
\hline 6 & $\begin{array}{l}\text { Menurut anda, bagaimana pengelolaan sumber } \\
\text { daya manusia (karyawan) di perusahaan ini? }\end{array}$ & 1,00 & 5,00 & 4,00 \\
\hline 7 & $\begin{array}{l}\text { Menurut anda, bagaimana hubungan TI dengan } \\
\text { proses bisnis yang telah berjalan saat ini? }\end{array}$ & 5,00 & 5,00 & 0 \\
\hline 8 & $\begin{array}{l}\text { Bagaimana keselerasan TI terhadap kebutuhan } \\
\text { bisnis anda? }\end{array}$ & 3,00 & 5,00 & 2,00 \\
\hline 9 & $\begin{array}{l}\text { Bagaimana peranan TI dalam pengelolaan } \\
\text { pemasok? }\end{array}$ & 5,00 & 5,00 & 0 \\
\hline 10 & $\begin{array}{l}\text { Bagaimana peranan TI dalam pengelolaan } \\
\text { kualitas? }\end{array}$ & 2,00 & 5,00 & 3,00 \\
\hline 11 & $\begin{array}{l}\text { Bagaimana pengelolaan risiko yang dilakukan } \\
\text { oleh TI? }\end{array}$ & 2,00 & 5,00 & 3,00 \\
\hline 12 & $\begin{array}{l}\text { Bagaimanakah pengelolaan keamanan TI yang } \\
\text { ada? }\end{array}$ & 5,00 & 5,00 & 0,00 \\
\hline & Rata-rata & $\mathbf{3 , 2 5}$ & $\mathbf{5 , 0 0}$ & \\
\hline
\end{tabular}

Adapun analisis dari hasil wawancara secara umum dapat dilihat dalam tabel-tabel sebagai berikut :

Tabel 5 Deskripsi Domain APO01

\begin{tabular}{|l|c|c|}
\hline Control Objective & Rata-Rata & Maturity Level \\
\hline $\begin{array}{l}\text { APO01 - Mengelola Kerangka } \\
\text { Kerja Manajemen TI }\end{array}$ & 1,00 & Initial \\
\hline \multicolumn{2}{|c|}{ Deskripsi COBIT : } \\
\hline - & $\begin{array}{l}\text { Pengelolaan manajemen TI yang berjalan saat ini masih memiliki banyak } \\
\text { kekurangan, berupa tidak adanya struktur oganisasi manajemen TI }\end{array}$ \\
- & $\begin{array}{l}\text { Penanggung jawab TI memiliki peran, dan tanggung jawab yang sama, } \\
\text { dikarenakan tidak adanya struktur organisasi sehingga dalam melakukan aktifitas } \\
\text { tidak terstruktur dengan baik. } \\
\text { - Tidak adanya rencana strategis untuk pengelolaan TI ke depannya, sehingga tidak } \\
\text { ada evaluasi kepatuhan terhadap kebijakan dan prosedur yang berlaku. }\end{array}$ \\
\hline
\end{tabular}

Berdasarkan tabel di atas, dapat diketahui bahwa Expected Maturity yang ditetapkan oleh Manajemen untuk domain APO adalah pada level 5,00 (Optimized) atas setiap subbabnya. Dari 12 pertanyaan yang menggambarkan Domain APO, gap tertinggi sebesar 4,00 terdapat pada APO 01 (Mengelola Kerangka Kerja Manajemen TI), APO 03 (Mengelola Arsitektur 
Perusahaan), dan APO 07 (Mengelola Inovasi TI). Hal ini menunjukkan bahwa pengelolaan untuk subbab domain ini harus diperbaiki karena sangat jauh dari harapan manajemen.

Tabel 6 Deskripsi Domain APO02

\begin{tabular}{|c|c|c|}
\hline Control Objective & Rata-Rata & Maturity Level \\
\hline $\begin{array}{l}\text { APO02 - Mengelola Strategi TI Selaras } \\
\text { dengan Bisnis }\end{array}$ & 5,00 & Optimized \\
\hline \multicolumn{3}{|c|}{ Deskripsi COBIT : } \\
\hline \multicolumn{3}{|c|}{$\begin{array}{l}\text { Pengelolaan strategi TI berupa adanya pengelolaan software dan hardware saat ini } \\
\text { sudah selaras dengan bisnis. Penanggungjawab TI mampu menyediakan software yang } \\
\text { dibutuhkan sehingga saat ini bisnis yang berjalan cukup lancer }\end{array}$} \\
\hline
\end{tabular}

Sedangkan pada subbab APO 04 (Mengelola Strategi TI selaras dengan bisnis), APO 03 (Mengelola Arsitektur Perusahaan), APO 08 (Mengelola Hubungan TI dengan bisnis), APO 10 (Mengelola pemasok) dan APO 13 (Mengelola Keamanan TI), tidak ada gap sehingga tidak diperlukan perubahan atas pengelolaan TI yang telah berjalan. Dalam domain ini, nilai gap bertingkat, dari yang paling tinggi $(4,00)$ hingga paling kecil $(0,00)$, sehingga pengelolaan yang ada perlu direview kembali dan menyesuaikan dengan saran pengelolaan yang ada sehingga mampu memenuhi harapan manajemen secara menyeluruh.

Rata - rata keseluruhan dari keduabelas pertanyaan ini adalah 3,25, yang berada pada level Defined, yang berarti prosedur distandardisasi dan didokumentasikan kemudian dikomunikasikan melalui pelatihan. Proses - proses ini harus diikuti. Prosedur ini belum lengkap, namun sudah memformalkan praktek yang berjalan.

Analisa Gap antara Current Maturity dan Expected Maturity ditampilkan melalui grafik yang dapat dilihat pada gambar 3.

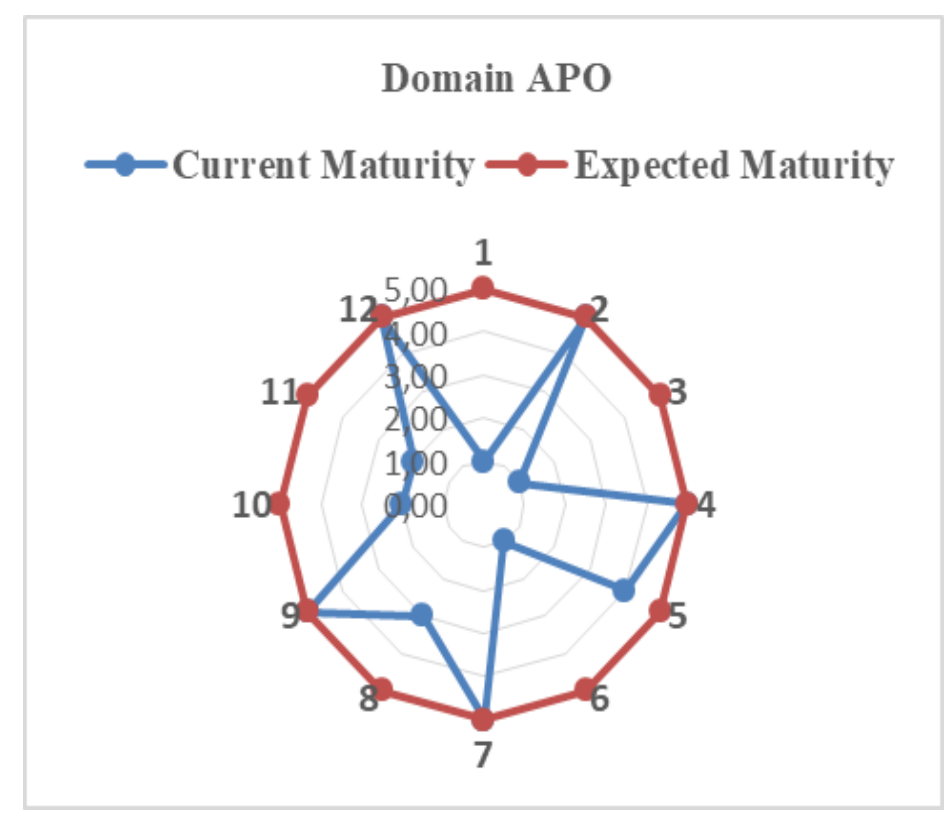

Gambar 3 Tampilan Grafik Current dan Target Maturity Level Domain APO

JSIKTI Vol. 2, No. 2, Desember 2019: $65-76$ 


\section{KESIMPULAN}

Berdasarkan hasil pembahasan yang telah disampaikan dalam bab sebelumnya, penulis dapat menarik kesimpulan sebagai berikut : Dari tiap domain, terdapat subbab - subbab yang sangat jauh dari harapan manajemen, sehingga diperlukan perhatian khusus berupa perbaikan pengelolaan secepatnya, dengan rekomendasi perbaikan sebagai acuan perbaikan tersebut. Perlu dibentuknya struktur organisasi manajemen TI sehingga terdapat penetapan tugas, wewenang, dan tanggungjawab terstruktur, Penetapan rencana strategis sehingga evaluasi terhadap kepatuhan terjadwal dengan baik, Penambahan menu purchase order sparepart khusus pesanan, Penambahan warning / reminder saat input KSG yang sudah lewat dari periode yang telah ditetapkan, Penambahan dan pemeliharaan computer, printer, dan mouse di beberapa divisi, dan Penambahan menu atau fitur yang dibutuhkan dalam software D-Pack Web

\section{SARAN}

Dilakukan audit lebih mendalam atas software yang digunakan dalam bisnis perusahaan, seperti D-Pack Web dan YDT (Yamaha Diagnostic Tools) untuk mengetahui kekurangan sistem sehingga fitur sistem lebih sesuai dengan kebutuhan bisnis.

\section{DAFTAR PUSTAKA}

[1] Syaputra, S. D, "Tata Kelola Teknologi Informasi Menggunakan Framework COBIT 5", PT Santani Agro Persada. IIB Darmajaya, 2017.

[2] Rizaldi, R. A, “Audit Tata Kelola Teknologi Informasi Menggunakan Framework COBIT 5 ( Studi Kasus: PT . Indocom Tambak Udang Lampung )", IIB Darmajaya Lampung, 2017.

[3] Sarno, R, "Audit Sistem \& Teknologi Informasi. (A. Herdiyanti, Ed.)", 1 ed. Surabaya: ITS Press, 2009.

[4] Jogiyanto, dan Abdillah, W, Sistem Tata Kelola Teknologi Informasi”, Yogyakarta: ANDI OFFSET, 2011.

[5] Gunawan, B., dan Pratama, F. A, "Perancangan Tata Kelola Teknologi Informasi", 1 ed. Yogyakarta: ANDI OFFSET, 2018.

[6] P.Sugiartawan,I.D.K.R. Rustina, R.W.S. Insani, "E-Government Media Informasi Alat Kelengkapan Dewan Provinsi Bali dan Media Diskusi Berbasis Website", J. Sist. Inf. dan Komput. Terap. Indones., vol. 2, no. 1, 2018.

[7] P.Sugiartawan, H.Rowa, N.Hidayat, " Sistem Pendukung Keputusan Kenaikan Jabatan Menggunakan Metode Profile Matching ", J. Sist. Inf. dan Komput. Terap. Indones., vol. 2, no. $1,2018$.

[8] Nugroho, I, "Peranan Teknologi Informasi Dalam Audit Sistem Informasi", I(2), 122130, 2009.

[9] ISACA, Kerangka COBIT 5, COBIT 4.1, BMI (Modeling Bussiness Information), Manajemen Tata Kelola, Jaminan Framework, Kerangka IT Risk. Major ISACA, 2012. 
[10] Muchsam, Y., Falahah, dkk, "Penerapan Gap Analysis Pada Pengembangan Sistem Pendukung Keputusan Penilaian Kinerja Karyawan", 2011

[11] Maliki, U., "Metode Pengumpulan Data Penelitian Kualitatif", 1-4, 2011. 